1 Winton Centre for Risk and Evidence Communication, Statistical Laboratory Centre for Mathematical Sciences, Cambridge, UK

david@statslab.cam.ac.uk Cite this as: BMJ 2020;370:m3259 http://dx.doi.org/10.1136/bmi.m3259 Published: 09 September 2020

\section{Use of "normal" risk to improve understanding of dangers of covid-19}

Accumulating data on deaths from covid-19 show an association with age that closely matches the "normal" risk we all face. Explaining risk in this way could help people understand and manage their response, says David Spiegelhalter

\section{David Spiegelhalter chair}

As covid-19 turns from a societal threat into a matter of risk management, it is vital that the associated risks are understood and clearly communicated. ${ }^{1}$ But these risks vary hugely between people, and so finding appropriate analogues is a challenge. Although covid-19 is a complex multisystem disease that can cause prolonged illness, here I focus solely on the risks of dying from covid-19 and explore the use of "normal" risk-the risk of death from all causes each year-as an aid to transparent communication.

\section{Population fatality risks in terms of normal risks}

The population fatality rate tells us the proportion of the total population getting infected and then dying with covid-19 over a specified time. This can be directly obtained from death registrations in which covid-19 is mentioned on the death certificate in England and Wales. ${ }^{2}$ It will include those dying both from and with the virus, while underestimating the true number of deaths linked to covid-19 because of underdiagnosis in people who did not display classic symptoms, were not tested, and so did not have covid-19 mentioned on the death certificate.

In the 16 weeks (112 days) between 7 March and 26 June 2020, 218354 deaths were registered in England and Wales, compared with an average of 159595 for this period over the past five years. This is an absolute increase of $37 \%$; $49607(84 \%)$ of these excess deaths had covid-19 mentioned on the death certificate. Figure 1 shows the age and sex specific population fatality rates on both logarithmic and linear scales, compared with the age and sex specific annual "hazards"-that is, the proportion of people of each age who do not reach their next birthday-obtained from the life tables provided by the Office for National Statistics ${ }^{3}$ and scaled to 16 weeks. excess of 58759 deaths, corresponding to a relative 


\section{Normal 16 Covid week risk death rate}
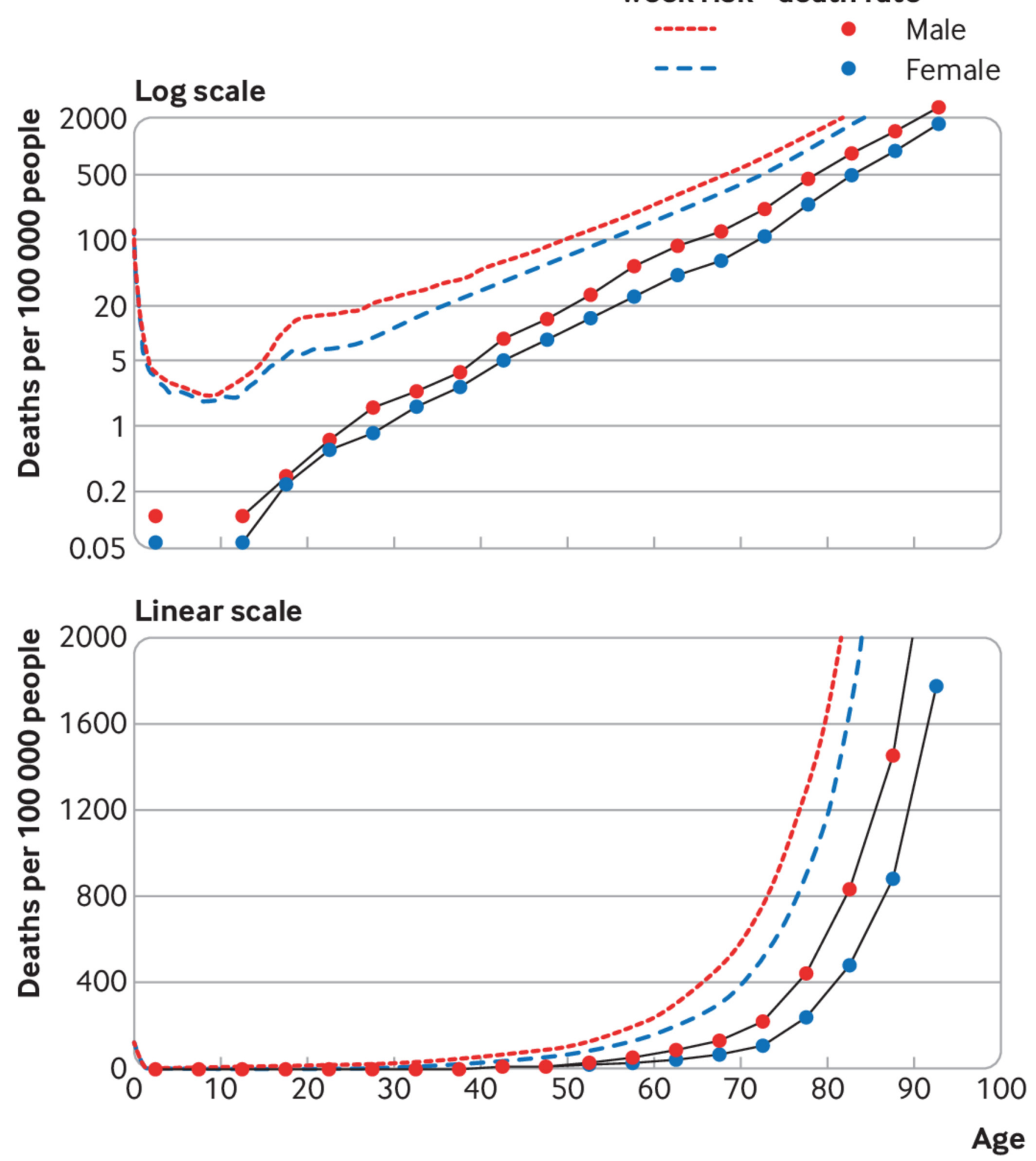

Fig 1 | Observed population fatality rates for 49607 deaths mentioning covid-19, registered in England and Wales between 7 March and 26 June 2020 . The covid-19 death rates create a remarkably straight line on a logarithmic scale (top), indicating an exponential increase of risk with age. The "normal" risk (dashed lines) is the actuarial annual mortality, scaled by a factor $16 / 52$ to reflect the risk over 16 weeks.

The actuarial risks show an early peak related to congenital diseases and birth trauma, then a minimum at around age 9 or 10 and a steady increase, which is remarkably linear apart from a bump in the late teens and early 20 associated with deaths from non-natural 
causes. This near linearity on a logarithmic scale corresponds to an exponential increase-from age 35, the annual hazard increases at an average $9.7 \%$ a year for men and $10.4 \%$ a year for women. This means that, in normal circumstances, the average annual risk of death doubles for each seven years of extra age (since a $10 \%$ a year increase (1.1) over seven years leads to a total increase of $1.1^{7}$, which is roughly 2 ).
The population fatality rates for covid-19 display even stronger linearity on the logarithmic scale. Table 1 shows the death rate during this 16 week period was around $12-13 \%$ higher for each year older, corresponding to doubling for every five to six additional years of age, and this relation is consistent from childhood to old age. On average, men experienced around $70 \%$ additional risk compared with women the same age. Other countries show a similar gradient. ${ }^{4}$

Table 1 | Estimated effects of sex and age on population fatality rates for covid-19 based on 49607 deaths registered in England and Wales between 7 March and 26 June 2020*

\begin{tabular}{|c|c|c|}
\hline & Estimate & $95 \%$ confidence interval \\
\hline Increased risk: each year older & 1.128 & 1.125 to 1.131 \\
\hline Years to double risk & 5.75 & 5.61 to 5.88 \\
\hline Increased risk: male $v$ female & 1.71 & 1.63 to 1.77 \\
\hline
\end{tabular}

* Based on a Poisson regression, log-linear assumption, with allowance for overdispersion. If the increased risk per year is c, the years to double risk, d, obeys the rule $2=c \mathrm{~cd}$, or $\mathrm{d}=\log (2) / \log (\mathrm{c})$.

The relation of covid-19 mortality risk with age is slightly steeper than it is for normal actuarial risk, but for ages over 45 the lines are fairly parallel, indicating that the average risk of catching and then dying from the virus were roughly proportional to the average normal risk over the same period.
The risks of catching and dying from the virus vary 10 ooo-fold depending on age, as shown in the linear graph, and it is challenging to communicate such a massive range. Table 2 represents an attempt to communicate the additional risk of dying from covid-19 in terms of extra days of normal risk, represented by the five year average for these 16 weeks in order to adjust for seasonal effects.

Table 2 | Deaths registered in 16 weeks between 7 March and 26 June 2020 in England and Wales: 49607 deaths with covid-19 on death certificate. Five year averages and populations from the Office for National Statistics 56

\begin{tabular}{|c|c|c|c|c|c|c|c|c|c|}
\hline Age (years) & $\begin{array}{l}\text { No of covid-19 } \\
\text { deaths }\end{array}$ & Population & $\begin{array}{c}\text { Covid-19 rate/ } 100 \\
000\end{array}$ & Covid-19 rate (\%) & $\begin{array}{l}\text { Covid-19 rate } \\
\text { (1 in ...) }\end{array}$ & $\begin{array}{l}\text { No of non-covid } \\
\text { deaths }\end{array}$ & 5 year average & $\begin{array}{c}\text { Covid- } 19 \text { as } \% \text { of } 5 \\
\text { year average }\end{array}$ & $\begin{array}{c}\text { Equivalent days of } \\
\text { normal risk }\end{array}$ \\
\hline $0-4$ & 3 & 3515430 & 0.1 & 0 & 1 in 1171810 & 848 & 932 & 0 & 0 \\
\hline $5-14$ & 3 & 7159102 & 0 & 0 & 1 in 2386367 & 138 & 179 & 2 & 2 \\
\hline $15-24$ & 33 & 6988755 & 0.5 & 0 & 1 in 211780 & 470 & 659 & 5 & 6 \\
\hline $25-34$ & 128 & 7998302 & 1.6 & 0 & 1 in 62487 & 1,141 & 1,295 & 10 & 11 \\
\hline $35-44$ & 369 & 7460856 & 4.9 & 0 & 1 in 20219 & 2,577 & 2,610 & 14 & 16 \\
\hline $45-54$ & 1283 & 8142528 & 15.8 & 0.02 & 1 in 6,346 & 6,577 & 6,449 & 20 & 22 \\
\hline $55-64$ & 3476 & 7019590 & 49.5 & 0.05 & 1 in 2,019 & 13565 & 12722 & 27 & 31 \\
\hline $65-74$ & 7319 & 5906928 & 124 & 0.12 & 1 in 807 & 27184 & 26617 & 28 & 31 \\
\hline $75-84$ & 16043 & 3476922 & 461 & 0.46 & 1 in 217 & 47729 & 45300 & 35 & 40 \\
\hline $85-89$ & 10160 & 918437 & 1110 & 1.1 & 1 in 90 & 30703 & 29108 & 35 & 39 \\
\hline $90+$ & 10790 & 528959 & 2040 & 2.0 & 1 in 49 & 37815 & 33722 & 32 & 36 \\
\hline All & 49607 & 59115809 & 83.9 & 0.08 & 1 in 1192 & 168747 & 159593 & 31 & 35 \\
\hline
\end{tabular}

For example, among nearly six million people aged 65-74 in England and Wales, 7319 were registered as dying from or with covid-19 over 16 weeks, a rate of around 124 in 100 ooo, or 1 in 807 . We would normally expect around 26617 deaths in this age group over this period, and so covid-19 represented a $28 \%$ increased risk. This is equivalent to around 31 days' extra risk of dying during 112 days of the epidemic.

The second row of table 2 shows that three deaths from covid-19 have been recorded among over 7 million schoolchildren aged 5 to 14 (around 1 in 2.4 million), an extremely low risk that represents only $2 \%$ of the average normal risk faced by this group. This amounts to around two days' extra risk of dying during the 112 days of the epidemic. In the same period this age group experienced 138 deaths from other causes.
At the other extreme, $2 \%$ ( 1 in 49) of all those aged over 90 in England and Wales were registered as dying with covid-19 in these 16 weeks; this represents around 4300 times the risk of catching and dying from covid-19 compared with 15-24 year olds. These 10 790 deaths can be compared with the average of 33722 for this period over the past five years, so the potential exposure to covid-19 represents an additional $32 \%$ over normal mortality risk. So living through this 112 day period of the epidemic is as if these people have on average been exposed to an extra 36 days' risk ( $32 \%$ of 112).

Taken as a whole, 1 in 1192 of the population died and had covid-19 on their death certificate, which represents a 31\% increase over the normal risk, equivalent to an extra 35 days over and above the 112 days to which they had been exposed, although this additional relative risk was far lower for under 45 s and extremely small for under 15 s. 
In summary, those 16 weeks (112 days) of the pandemic led to those aged over 55 experiencing around five weeks' extra risk, while younger people were exposed to steadily smaller amounts: for schoolchildren it corresponded to just two additional days.

These are observed historical rates in the population and cannot be quoted as the future risks of getting covid-19 and dying. The risks of infection will be altered by factors that limit exposure and have dropped as the epidemic has been brought under control. There may also have been some selection of frail elderly people, bringing their deaths forward and leaving a temporarily more resilient cohort.

\section{Infection fatality risks in terms of normal risks}

In contrast to the population fatality rate, we might expect the infection fatality rate-that is, the risk of death if infected-to remain fairly stable over time.
In March 2020 researchers from Imperial College London published an influential report containing age specific risks of dying after infection with SARS-CoV-2. ${ }^{7}$ They estimated an overall infection fatality rate in the UK of $0.9 \%$, with a $95 \%$ uncertainty interval of $0.4 \%$ to $1.4 \%$, and provided rates and intervals for different age groups, with both sexes combined. Uncertainty intervals corresponded to a relative error of $\pm 55 \%$, showing the caution about these early estimates based on experience in Wuhan and aboard the Diamond Princess cruise ship.

In March 2020 I compared these estimates with the annual actuarial risks shown in figure 1 and found the agreement was reasonable, ${ }^{8}$ with the covid-19 risk estimates following a similar pattern to the background risk (fig 2, top). 


\section{Normal annual risk}

-.--.- Male
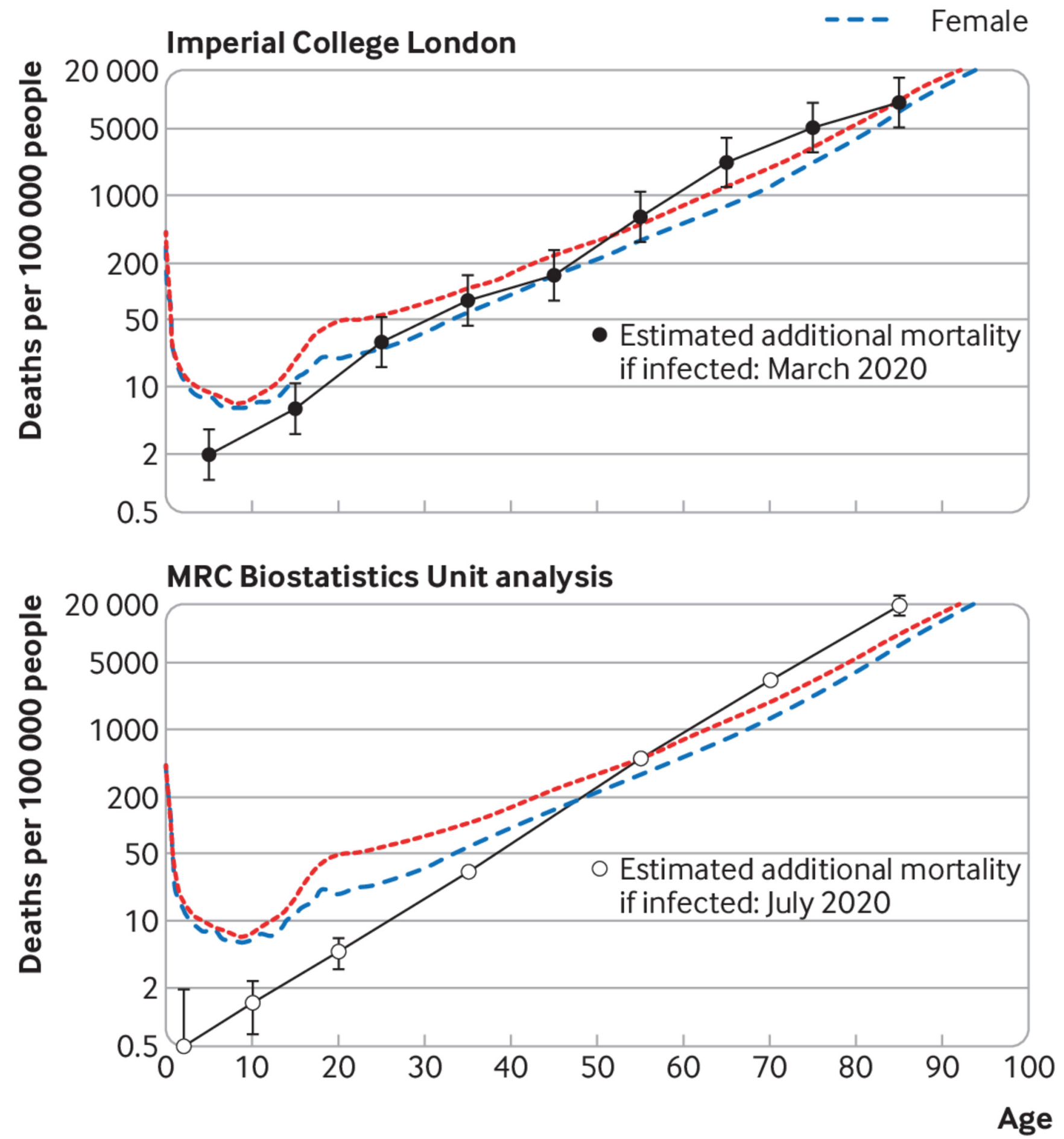

Fig 2 | Estimated infection fatality rates with covid-19 superimposed on background annual risk. Top: estimated covid-19 infection fatality rates are from Imperial College London, March 2020. Error bars on the estimated age specific covid- 19 mortality assume a relative error of $\pm 55 \%$. Bottom: estimated covid- 19 infection fatality rates from MRC Biostatistics Unit analysis, July 2020.

This agreement between the estimated covid-19 risks and the average annual mortality rates suggests that, based on the figures provided by the Imperial College team in March 2020, being infected with SARS-CoV-2 contributes about a year's worth of extra risk of dying 
for those aged over 20 and less than half this risk for those aged under 20. There is a simple reality check on this figure. Ferguson et $\mathrm{al}^{7}$ estimated that if the virus went completely unchallenged, around $80 \%$ of people would be infected and there would be around 510 ooo deaths. So if everyone got infected we would presumably expect $510000 \times 100 / 80=637500$ deaths, which is fairly close to the "normal" annual total of around 616 ooo deaths in the UK (2018).

Unfortunately, the message that covid-19 risk was about the same as the annual risk (and hence that catching the virus roughly doubles the risk of dying this year) was misinterpreted by some as meaning that it did not increase the annual risk at all. In fact, if the risk of dying this year from covid-19 is $p$, and the risk of independently dying from something else is also $p$, then probability theory tells us that the overall risk of dying this year is one minus the chance of surviving both hazards - that is, $1-(1-p)(1-p)$ or $2 p-p^{2}$. For low $p$, this will be very close to $2 p$, and so it is generally fine to say that covid-19 would roughly double the risk of dying. But if you were frail and had a $60 \%$ risk of dying next year, then with infection this would rise to $2 \times 0.6-0.6^{2}=0.84$, so altogether you would have an $84 \%$ chance of dying. (The events may also not be independent: survivors may be weakened by the disease or show increased resilience.)

The true infection fatality rate remains contested, with one review claiming a global rate of $1.04 \%,{ }^{9}$ while another has claimed a range from $0.02 \%$ to $0.4 \% .^{10}$ In July, the MRC Biostatistics Unit estimated updated infection fatality rates for the UK (fig 2, bottom). ${ }^{11}$ These correspond to an overall rate of $1.3 \%(1.1 \%$ to $1.5 \%)$, rather more than the early estimates from March, and also show a steeper gradient than the background risk, increasing at $12.8 \%$ per additional year of age, precisely that observed for the population fatality rates (fig 1 ). This steeper gradient suggests that the additional risk from being infected is rather more than the normal annual risk for those over 55, and rather less than the annual risk for those under 55.

All this analysis refers to averages over populations, and although age seems to be the overwhelmingly dominant influence on mortality, clearly other factors affect individual risk. More than $90 \%$ of people who have died with covid-19 had pre-existing medical conditions..$^{12}$ However, it may be reasonable, to a first approximation, to assume these comparisons apply to more highly stratified groups. The idea that covid-19 multiplies the "normal risk" of dying in the following year forms the basis for the analysis of Banerjee et al, ${ }^{13}$ who assume a fixed additional relative risk from covid-19, such as 0.5 ( 6 months' normal risk) to 1 (a year's normal risk) to be applied to actuarial estimates for one year mortality based on age, sex, and pre-existing conditions.

Importantly, all the risks quoted are the average (mean) risks for people of the relevant age but are not the risks of the average person. This is because, both for covid-19 and in normal circumstances, much of the risk is held by people who are already chronically ill. So for the large majority of healthy people, their risks of either dying from covid-19, or dying of something else, are much lower than those quoted here. Of course, while death is the most serious and easily recorded outcome, information is growing on the number of people experiencing prolonged symptoms of covid-19. This mounting problem presents a whole new challenge for surveillance, risk assessment, and risk communication.

\section{Conclusions}

The UK has experienced some of the highest per-capita mortality from covid-19 of any country. The covid-19 population fatality rate over the 16 week (112 day) peak of the epidemic in England and
Wales was equivalent to those over 55 experiencing around 5 weeks extra mortality risk above "normal," and steadily less for younger age groups, reducing to just two extra days for schoolchildren.

The infection fatality rate was estimated back in March to be roughly equivalent to the age specific annual mortality: currently it seems to be slightly more than a year's worth for over 55 s and less than this for under 55 s.

Normal risk appears a reasonable comparator for interpreting both population and infection fatality risks, although incorporation in any public facing tool would require careful evaluation, especially in light of the growing concerns about the prolonged impacts of infection. It should always be remembered that these are risks to the individual: there is still a responsibility to consider the potential risks an individual may cause to others.

\section{Key messages}

- It is difficult to communicate the huge range of individual mortality risks from covid-19 experienced by people of different ages.

- For the general population, the risk of catching and then dying from covid-19 during 16 weeks of the pandemic was equivalent to experiencing around 5 weeks extra "normal" risk for those over 55 , decreasing steadily with age, to just 2 extra days for schoolchildren

- For those over 55 who are infected with covid-19, the additional risk of dying is slightly more than the "normal" risk of death from all other causes over one year, and less for under 55 s.

- Analogy with normal risk seems an appropriate and useful tool for risk communication of lethal risk, although it does not deal with longer term harm to survivors.

Contributors and sources: DS is a statistician who conducted all the analyses, wrote the code to produce the graphics, and wrote the paper.

Competing interests: I have read and understood BMJ policy on declaration of interests and have no relevant interests to declare.

Provenance and peer review: Not commissioned; externally peer reviewed.

The David and Claudia Harding Foundation provide funding for the Winton Centre for Risk and Evidence Communication.

Smith GD, Spiegelhalter D. Shielding from covid-19 should be stratified by risk. BMJ 2020;369:m2063. doi: 10.1136/bmj.m2063 pmid: 32467287

2 Office for National Statistics. Deaths registered weekly in England and Wales, provisional [Internet]. 2020 [cited 2020 May 30]. Available from: https://www.ons.gov.uk/peoplepopulatio nandcommunity/birthsdeathsandmarriages/deaths/bulletins/deathsregisteredweeklyinenglandandwalesprovisional/weekending15may2020

Office for National Statistics. National life tables, UK. 2019. https://www.ons.gov.uk/peoplepopulationandcommunity/birthsdeathsandmarriages/lifeexpectancies/bulletins/nationallifetablesunit edkingdom/2016to2018

$4 \quad \mathrm{Ng}$ J, Bakrania K, Falkous C, Russell R. Covid-19 mortality rates by age and gender: why is the disease killing more men than women?RGA 2020 Jul 10. https://rgare.com/knowledge-center/media/research/covid-19-mortality-rates-by-age-and-gender-why-is-the-disease-killing-more-menthan-women

5 Office for National Statistics. Five-year average weekly deaths registered in England and Wales, by gender and age groupings . 2020 https:/www.ons.gov.uk/peoplepopulationandcommunity/birthsdeathsandmarriages/deaths/adhocs/11644fiveyearaverageweeklydeathsregisteredinenglandandwalesbygenderandagegroupings

6 Office for National Statistics. All data related to Population estimates for the UK, England and Wales, Scotland and Northern Ireland, provisional: mid-2019. 2020. https://www.ons.gov.uk/peoplepopulationandcommunity/populationandmigration/populationestimates/bulletins/annualmidyearpopulationestimates/mid2019/relateddata

Ferguson NM, et al. Report 9: Impact of non-pharmaceutical interventions (NPIs) to reduce COVID-19 mortality and healthcare demand. 2020. https://www.imperial.ac.uk/mrc-global-infectious-disease-analysis/news-wuhan-coronavirus/

8 Spiegelhalter D. How much 'normal' risk does Covid represent? Medium 2020 https://medium.com/wintoncentre/how-much-normal-risk-does-covid-represent-4539118e1196

9 Grewelle R, Leo GD. Estimating the global infection fatality rate of covid-19. medRxiv 2020.05.11.20098780.[Preprint.] doi: 10.1101/2020.05.11.20098780 
10 Ioannidis J. The infection fatality rate of COVID-19 inferred from seroprevalence data. medRxiv 2020.05.13.20101253.[Preprint.] doi: 10.1101/2020.05.13.20101253

11 Birrell P, Blake J, van Leeuwen E, de Angelis D, Biostatistics Unit MRC, COVID-19 Working Group. COVID-19: nowcast and forecast. 2020. https://www.mrc-bsu.cam.ac.uk/now-casting/

12 Office for National Statistics. Deaths involving COVID-19, England and Wales: deaths occurring in June 2020. 2020. https://www.ons.gov.uk/peoplepopulationandcommunity/birthsdeathsandmarriages/deaths/bulletins/deathsinvolvingcovid19englandandwales/deathsoccurringinjune2020\#characteristics-of-those-dying-from-covid-19

13 Banerjee A, Pasea L, Harris S, etal. Estimating excess 1-year mortality associated with the COVID-19 pandemic according to underlying conditions and age: a population-based cohort study. Lancet 2020;395:1715-25. doi: 10.1016/S0140-6736(20)30854-0 pmid: 32405103

This article is made freely available for use in accordance with BMJ's website terms and conditions for the duration of the covid-19 pandemic or until otherwise determined by BMJ. You may use, download and print the article for any lawful, non-commercial purpose (including text and data mining) provided that all copyright notices and trade marks are retained. 